\title{
"The plug and the bug" - a case of coronary embolism in bacterial endocarditis
}

\author{
Diego Arroyo ${ }^{a}$, Stéphane Cook ${ }^{a}$, Daniel Hayoz ${ }^{b}$, Mario Togni ${ }^{a}$ \\ a Department of Cardiology, University and Hospital Fribourg, Switzerland \\ b Department of Internal Medicine, University and Hospital Fribourg, Switzerland
}

\section{Summary}

Systemic embolism is a classic complication of infective endocarditis. Coronary involvement and acute myocardial infarction (MI) are rare and increase mortality significantly. Recognising this unusual entity is crucial to provide adequate care. Percutaneous coronary intervention and thrombus aspiration is preferred to thrombolysis, which classically increases intracerebral haemorrhage risk. The present article describes the case of an acute inferior ST-elevated MI due to a Streptococcus salivarius endocarditis in a patient with known bicuspid aortic valve.

Key words: bacterial endocarditis; septic embolism; coronary embolism; myocardial infarct

\section{Case report}

A 79 year-old female with prior history of hypertension and moderate aortic insufficiency due to bicuspid aortic valve presented to the emergency department with STelevation myocardial infarction (MI). She complained of acute retro-sternal chest pain and left arm radiation of 2 hours duration. The presentation followed a one-month period of fatigue, weight-loss and progressive dyspnea. Physical examination revealed an acutely ill lady. Non invasive blood pressure was 150/60 mm Hg on both sides; pulse regular at 100 beats per minute; respiratory rate at 20/minute; saturation $97 \%$ under $2 \mathrm{~L} / \mathrm{min}$ oxygen and temperature was $37.9^{\circ} \mathrm{C}$. Significant signs were a rapid upstroke followed by quick collapse of peripheral pulses, an enlarged hyperdynamic cardiac apical impulse, a blowing pandiastolic decrescendo murmur in the left upper sternal border, a midsystolic ejection murmur with carotid radiation and no extra heart sounds. Pulmonary auscultation was consistent with bilateral basal crackles. Chest radiograph revealed a marked cardiomegaly and dilation of the aortic knob and root but no signs of widened mediastinum or pulmonary

Funding / potential competing interests: No financial support and no other potential conflict of interest relevant to this article were reported. congestion. Troponin Ic was 0.35 $\mathrm{ug} / \mathrm{L}$, white blood cell count of 13.5 G/L with normal differential and a C-reactive protein of $60 \mathrm{mg} / \mathrm{L}$, and the rest of the laboratory work-up was unremarkable.
On arrival, the 12-lead electrocardiogram (ECG) showed normal sinus rhythm, first-degree atrioventricular block and a $2 \mathrm{~mm}$ ST-elevation in leads II, III avF, V5 and V6 (fig. 1A). Therapy was initiated with aspirin $500 \mathrm{mg}$, heparin $5000 \mathrm{U}$ and clopidogrel $600 \mathrm{mg}$. An urgent coronary angiography revealed the distal occlusion of a marginal branch of the circumflex artery but otherwise normal coronary arteries (fig. 1B). The aortogram showed significant ascending aorta dilatation (fig. 1C) as well as severe aortic valve regurgitation. The left ventricular ejection fraction was deemed normal with inferolateral hypokinesia. Considering the history and presentation, a septic embolus was thought to be the cause of the occlusion and, due to vessel tortuosity, distal lesion and spontaneous symptom alleviation no intravascular treatment was attempted. Peak troponin Ic was $12.3 \mathrm{ug} / \mathrm{L}$ and total CK $545 \mathrm{U} / \mathrm{L}$. Four different peripheral blood cultures grew penicillin sensitive Streptococcus salivarius (minimum inhibitory concentration $<0.125 \mathrm{mg} / \mathrm{L}$ ). A trans-oesophageal echocardiogram demonstrated a calcified and moderately remodelled bicuspid aortic valve with no evidence of vegetation or abscess and a normal mitral valve. All other findings were in line with the angiographic assessment. The abdominal scan showed a superior splenic infarction and the brain MRI was consistent with multiple, bilateral, embolic lesions with secondary haemorrhage (fig. 1D). The retina, skin and other organs were free from embolic complications. The patient was treated with i.v. ceftriaxone $2 \mathrm{~g}$ daily for 4 weeks, all subsequent blood cultures were negative and she remained symptom-free. The severe aortic regurgitation warranted a close cardiological follow-up and to date, the patient has had no further complaints.

Correspondence:

Diego Arroyo, MD

Department of Cardiology

University \& Hospital Fribourg

$\mathrm{CH}-1708$ Fribourg

Switzerland

da.arroyo[at]gmail.com 


\section{Figure 1}

Panel A: ECG demonstrating normal sinus rhythm, first degree atrioventricular block and ST-segment elevation in II, III, avF, V5-V6.

Panel B: Coronary angiogram demonstrating an acute occlusion $\left({ }^{*}\right)$ of a distal obtuse marginal artery (OMA) but otherwise normal coronaries. $L A D=$ left anterior descending

Panel C: Aortogram showing dilatation of the ascending aorta due to bicuspid aortic valve.

Panel D: Brain MRI - T2 flair and T1 sequences demonstrating a left posterior temporal and right lateral temporal lesion compatible with embolus and hemorrhagic transformation.
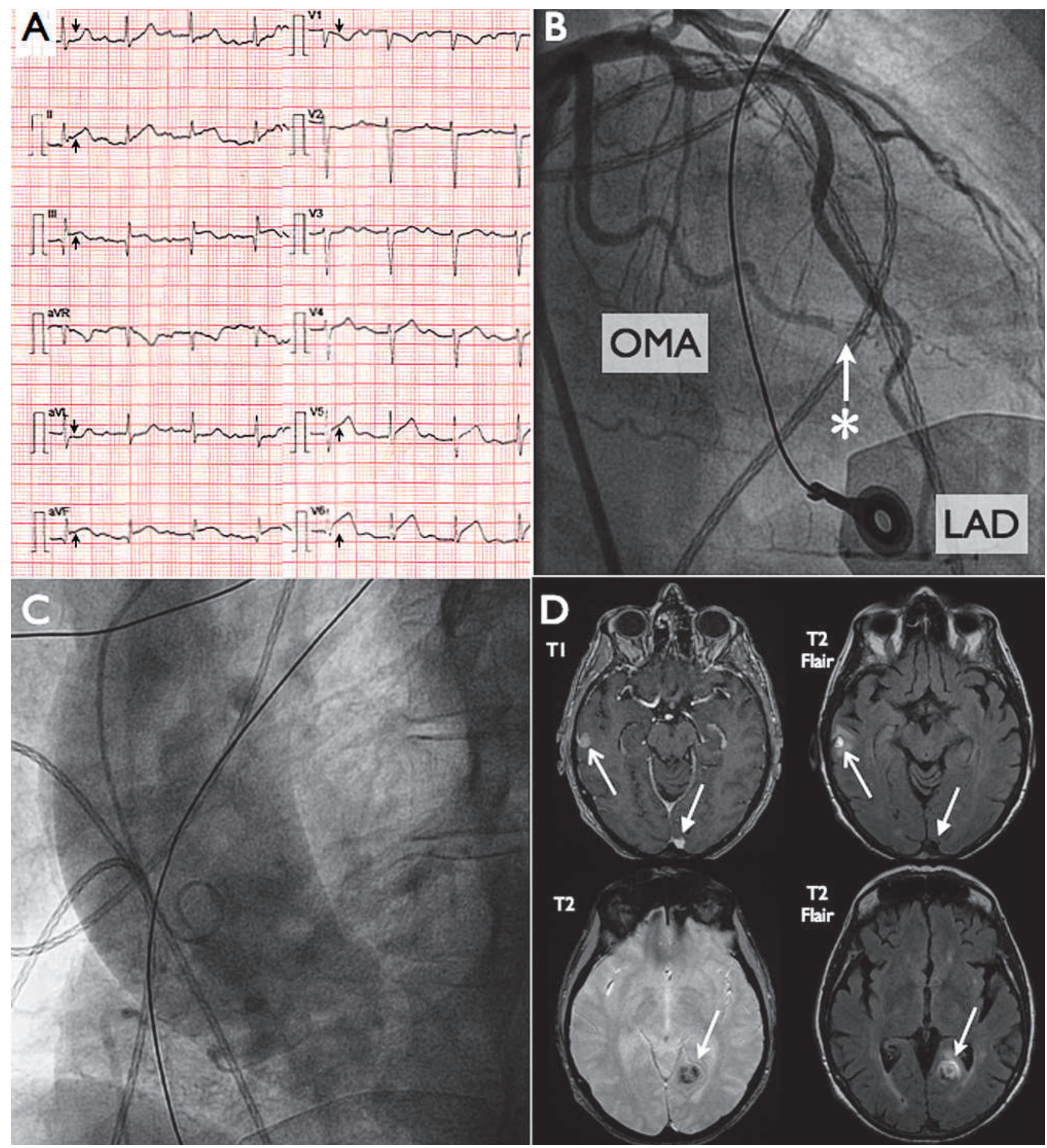

\section{Discussion}

In 1856, Rudolf Virchow was the first to describe coronary embolism as a complication of bacterial endocarditis. Autopsy studies in the mid 20th century revealed that it was found in up to $40 \%$ of patients with fatal bacterial endocarditis [1]. Coronary involvement leading to $\mathrm{MI}$ is nevertheless a rare condition with retrospective studies accounting for incidences of 0.3 to $3 \%$ $[2,3]$. The prognosis is difficult to quantify, but there is 
a clear trend towards excess mortality when compared to those without septic coronary embolism [4]. Virtually any described microorganism causing endocarditis may be involved but Streptococci are thought to be the most commonly isolated pathogen [5].

Certain angiographic features such as normal coronary arteries, abrupt termination of blood flow or absence of collateral vessels may suggest embolism [6]. The left-anterior descending (LAD) coronary artery is by far the most commonly involved. It is noteworthy to remember that not all MIs are due to coronary embolism. Other conditions have been described such as direct obstruction of coronary ostia due to aortic cusp vegetation, severe aortic insufficiency with low diastolic pressures or para-aortic abscess compression of the left main coronary artery [7].

In 1972, Pfeifer was the first to describe a successful surgical reperfusion of the LAD in a patient with MI due to septic coronary embolus [8]. Thrombolysis was later attempted with, over the years, periodic case reports of fatal intracerebral haemorrhages probably due to undetected cerebral mycotic aneurysms, such that it is now considered a relative contraindication $[9,10]$. The most convincing management seems to be the percutaneous coronary approach with, when possible, embolus aspiration. However, this is not without potential adverse consequences, as angioplasty, with or without stent deployment, may lead to mycotic aneurysm or pannus migration [9, 11, 12]. Moreover, stenting in an infected area could lead to early stent thrombosis [13]. The optimal treatment strategy has yet to be determined but it is unlikely, given the small amount of cases, that any will be based on solid evidence. We would advise coronary angiography to be considered as the first approach.
This case illustrates that when confronted with myocardial infarction in unusual settings, one should think of endocarditis as an embolic source. In doing so, the patient benefits from prompt and vital antibiotics but caution should be drawn when attempting reperfusion, as adverse consequences lie behind the perilous path of each chosen strategy.

\section{References}

1 Brunson JG. Coronary embolism in bacterial endocarditis. Am J Pathol. 1953;29(4):689-701.

2 Fabri J Jr., Issa VS, Pomerantzeff PM, Grinberg M, Barretto AC, Mansur, AJ. Time-related distribution, risk factors and prognostic influence of embolism in patients with left-sided infective endocarditis. Int J Cardiol. 2006;110(3):334-9.

3 Manzano MC, Vilacosta I, San Roman JA, Aragoncillo P, Sarria C, Lopez $\mathrm{D}$, et al. Acute coronary syndrome in infective endocarditis. Rev Esp Cardiol. 2007;60(1):24-31.

4 Yeoh J, Sun T, Hobbs M, Looi JL, Wong S. An uncommon complication of infective bacterial endocarditis. Heart Lung Circ. 2012;21(12):811-4.

5 Khan F, Khakoo R, Failinger C. Managing embolic myocardial infarction in infective endocarditis: current options. J Infect. 2005;51(3):e101-5.

6 Roxas CJ, Weekes AJ. Acute myocardial infarction caused by coronary embolism from infective endocarditis. J Emerg Med. 2011;40(5):509-14

7 Bloechlinger S, Nebiker M, Windecker S. Unusual cause of myocardial infarction and congestive heart failure in a patient with prosthetic valve endocarditis. Catheter Cardiovasc Interv. 2013: in press.

8 Pfeifer JF, Lipton MJ, Oury JH, Angell WW, Hultgren HN. Acute coronary embolism complicating bacterial endocarditis: operative treatment. Am J Cardiol. 1976;37(6):920-2.

9 Herzog CA, Henry TD, Zimmer SD. Bacterial endocarditis presenting as acute myocardial infarction: a cautionary note for the era of reperfusion. Am J Med. 1991;90(3):392-7.

10 Overend L, Rose E. Uncertainties in managing myocardial infarction associated with infective endocarditis. Exp Clin Cardiol. 2012;17(3):144-5.

11 Dhawan S, Schreiber D, McCauley CS, Maki, HS, Tak T. Surgical management of mycotic aneurysm of the left anterior descending artery. Can J Cardiol. 2005;21(8):701-3.

12 Donal E, Coisne D, Valy Y, Allal J, Christaens L, Barraine R. Myocardial infarction caused by septic embolism during mitral endocarditis. Arch Mal Coeur Vaiss. 1999;92(2):253-7.

13 Dieter RS. Coronary artery stent infection. Clin Cardiol. 2000;23(11): 808-10. 